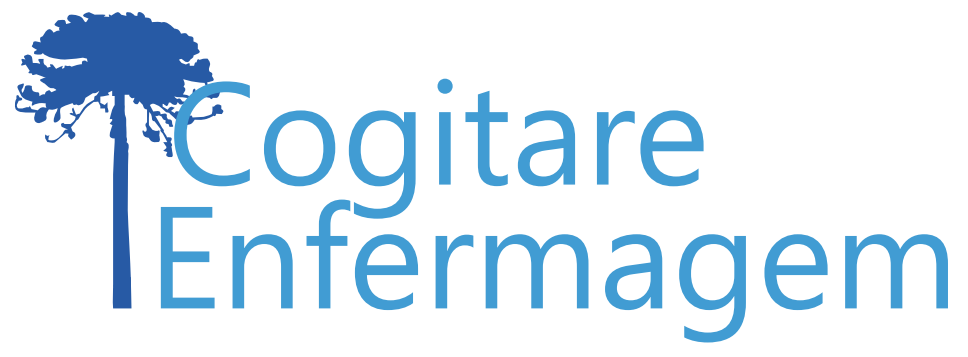

\title{
VALIDAÇÃO DE ÁLBUM SERIADO PARA ENFERMEIROS DA ATENÇÃO BÁSICA SOBRE VIOLÊNCIA DOMÉSTICA CONTRA A MULHER*
}

Viviane Maria de Pádua Rios Magalhães ${ }^{1}$, Rosimeire Ferreira dos Santos ${ }^{2}$, Carmen Viana Ramos ${ }^{3}$, Lucíola Galvão Gondim Corrêa Feitosa ${ }^{4}$, Eliana Campêlo Lago ${ }^{5}$, Elayne Kelly Sepedro Sousa ${ }^{6}$, Camila Aparecida Pinheiro Landim Almeida ${ }^{7}$

\section{RESUMO}

Objetivo: validar o conteúdo e a aparência de um álbum seriado para enfermeiros da atenção básica sobre violência doméstica contra a mulher.

Método: estudo metodológico, de validação de aparência e conteúdo, desenvolvido em Teresina, Piauí, Brasil, no ano de 2018. Coletou-se os dados pelo envio dos instrumentos de avaliação via e-mail para especialistas selecionados na Plataforma Lattes. $\mathrm{Na}$ análise utilizou-se o Índice de Validade de Conteúdo com valor estabelecido de 0,78.

Resultados: participaram 15 especialistas, com experiência em tecnologias educativas e/ou violência contra mulher, a maioria com doutorado e graduado em enfermagem. Quanto à estrutura e apresentação, objetivos e relevância, todos os itens foram considerados validados pelos especialistas. O Índice de Validade de Conteúdo global da tecnologia educativa foi 0,93. Conclusão: o álbum seriado foi validado quanto ao conteúdo e aparência, sugerindo que esta tecnologia educativa possibilita ações de educação em saúde realizadas por enfermeiros da Atenção Básica.

DESCRITORES:Violência Contraa Mulher;Educação em Saúde; Estudos de Validação; Enfermagem; Saúde Pública.

*Artigo extraído da dissertação de mestrado "Elaboração e validação de um álbum seriado sobre violência doméstica contra a mulher para enfermeiros". Centro Universitário Uninovafapi, 2018.

\section{COMO REFERENCIAR ESTE ARTIGO:}

Magalhães VM de PR, Almeida CAPL, Santos RF dos, Ramos CV, Feitosa LGGC, Lago EC. Validação de álbum seriado para enfermeiros da atenção básica sobre a violência doméstica contra a mulher. Cogitare enferm. [Internet]. 2020 [acesso em "colocar data de acesso, dia, mês abreviado e ano"]; 25. Disponível em: http:// dx.doi.org/10.5380/ce.v25i0.62729.

Este obra está licenciado com uma Licença Creative Commons Atribuição 4.0 Internacional.

${ }^{1}$ Advogada. Mestre em Saúde da Família. Servidora Pública do Ministério Público do Estado do Piauí. Teresina, PI, Brasil. (ㄷ ${ }^{2}$ Farmacêutica. Doutora em Produtos Naturais e Sintéticos Bioativos. Docente da Universidade Federal do Piauí. Teresina, PI, Brasil.

${ }^{3}$ Nutricionista. Doutora em Saúde da Criança e da Mulher. Docente do Centro Universitário Uninovafapi. Teresina, PI, Brasil. ${ }^{4}$ Enfermeira. Doutora em Políticas Públicas. Docente do Centro Universitário Uninovafapi. Teresina, PI, Brasil. ()

${ }^{5}$ Enfermeira e Odontóloga. Docente da Universidade Estadual do Maranhão. São Luís, MA, Brasil. 0

${ }^{6}$ Enfermeira. Graduada em Enfermagem pelo Centro Universitário Uninovafapi. Teresina, PI, Brasil. ()

${ }^{7}$ Enfermeira. Doutora em Ciências. Investigadora do Programa de Doutoramento em Enfermagem da Universidade Católica

Portuguesa. Porto, Portugal. (-) 


\title{
VALIDATION OF A SERIAL ALBUM ON DOMESTIC VIOLENCE AGAINST WOMEN FOR PRIMARY CARE NURSES
}

\begin{abstract}
Objective: to validate the content and appearance of a serial album on domestic violence against women for primary care nurses.

Method: a methodological study, of appearance and content validation, developed in Teresina, Piauí, Brazil, in 2018. The data were collected by sending the evaluation instruments via e-mail to selected specialists on the Lattes Platform. In the analysis, the Content Validity Index was used with an established value of 0.78 .

Results: 15 specialists participated, with experience in educational technologies and/or violence against women, most of them have doctorates and nursing degrees. Regarding structure and presentation, objectives and relevance, all items were considered validated by experts. The global Content Validity Index of the educational technology was 0.93. Conclusion: The serial album has been validated for content and appearance, suggesting that this educational technology enables health education actions performed by nurses of Basic Care.
\end{abstract}

DESCRIPTORS: Violence Against Women; Health Education; Validation Studies; Nursing; Public Health.

\section{VALIDAÇIÓN DE ÁLBUM SERIADO PARA ENFERMEROS DE ATENCIÓN PRIMARIA SOBRE VIOLENCIA DOMÉSTICA CONTRA LA MUJER}

\begin{abstract}
RESUMEN:
Objetivo: validar el contenido y la apariencia de un álbum seriado para los enfermeros de atención primaria sobre violencia doméstica contra la mujer.

Método: estudio metodológico, para validación de apariencia y contenido, desarrollado en Teresina, Piauí, Brasil, en el año 2018. La recolección de datos se realizó a través del envío de los instrumentos de evaluación a los especialistas seleccionados en la Plataforma Lattes, por vía de correo electrónico. El valor del índice de validez de contenido establecido para el análisis fue de 0,78.

Resultados: participaron 15 especialistas, con experiencia en tecnologías educativas y / o violencia contra las mujeres, la mayoría, con doctorados o graduados en enfermería o En cuanto a los ítems estructura, presentación, objetivos y relevancia, todos se consideraron validados por los expertos. El índice de validez de contenido global para la tecnología educativa fue de 0,93.

Conclusión: el álbum seriado fue validado en términos de contenido y apariencia, lo que sugiere que esta tecnología educativa permite acciones de educación en salud realizadas por enfermeros de atención primaria.
\end{abstract}

DESCRIPTORES: Violencia contra la mujer; Educación en salud; Estudios de validación; Enfermería; Salud pública. 
A violência contra a mulher é uma violação aos diretos humanos e constitui um problema de saúde pública. No Brasil, a análise de 512 casos de atendimentos revelou que a violência física foi a mais frequente $(65,0 \%)$, seguida pela psicológica $(60,4 \%)$, moral $(17 \%)$, patrimonial $(10,4 \%)$ e sexual $(6,1 \%)^{(1)}$. No que tange ao panorama internacional, estudo realizado em Haryana, na Índia, evidenciou que $37 \%$ das mulheres indianas já sofreram violência doméstica alguma vez na vida e $28,9 \%$ relataram que sofrem violência doméstica(2).

Este fenômeno vem ganhando visibilidade, tornando-se alvo de debates e estimulando o surgimento de legislações específicas, como a Lei Federal 10.778/2003, que determina a notificação compulsória nas situações de violência contra a mulher em serviços de saúde, e a Lei 11.340/2006, conhecida como Lei Maria da Penha, que preconiza meios para combater a violência doméstica e familiar contra a mulher ${ }^{(3-6)}$.

A Lei Maria da Penha descreve a violência doméstica contra a mulher como qualquer ato ou conduta baseado no gênero que cause a morte, dano ou sofrimento físico, sexual, psicológico, moral ou patrimonial no âmbito da unidade doméstica, familiar ou em qualquer relação íntima de afeto, no qual o agressor conviva ou tenha convivido com a mulher, independente de coabitação(5).

Pesquisas registram que mulheres que sofreram violência procuram mais os cuidados em serviços de saúde, locais em que podem romper o silêncio sobre a situação de violência doméstica vivenciada. Assim, as Unidades Básicas de Saúde são a "porta de entrada" e grande possibilidade para a identificação desse tipo de violência e acolhimento da mulher ${ }^{(4,7)}$.

Por ser um fenômeno multifatorial, a violência contra a mulher exigiu a criação de políticas e programas em diversas áreas, como jurídica, segurança e saúde. Dentre as estratégias de prevenção e combate, a elaboração e a divulgação de materiais educativos relacionados à temática traduzem estratégias relevantes para a promoção da informação, debate e enfrentamento da violência contra a mulher, pois podem contribuir para o esclarecimento da sociedade e dar visibilidade ao problema(3).

Contudo, ainda se observa escassez de estudos sobre a elaboração de materiais educativos voltados à prevenção da violência doméstica contra a mulher, o que pode estar associado à recente efetivação destas estratégias e às condições objetivas de produção das informações no âmbito da prevenção ${ }^{(3)}$. Assim, a elaboração do álbum seriado justificase diante da carência na literatura de material educativo sobre a violência doméstica contra a mulher e, ainda, pelo fato de ser uma importante tecnologia educativa que poderá contribuir como ferramenta para os enfermeiros da Atenção Básica nas ações de educação voltadas à saúde da mulher.

Nesse contexto, ressalta-se a importância de estimular a elaboração e utilização de tecnologias educativas capazes de intermediar o diálogo entre enfermeiros e mulheres, em busca da produção conjunta do conhecimento sobre a temática da violência doméstica. Além disso, essas tecnologias são consideradas materiais que contribuem para ampliar as possibilidades dos enfermeiros da Atenção Básica nas práticas direcionadas ao cuidado da mulher vítima de violência doméstica ${ }^{(8,9)}$.

Diante disso, este estudo objetivou validar o conteúdo e a aparência de álbum seriado para enfermeiros sobre violência doméstica contra a mulher, com vistas a uma intervenção educativa que contribua com as ações dos enfermeiros no âmbito da Atenção Básica no cuidado à mulher, o que possibilita uma reflexão sobre a formação e o desenvolvimento de melhores práticas para a saúde das mulheres. 
Estudo metodológico de elaboração de material educativo e validação de aparência e conteúdo, baseado nos modelo de construção de materiais educativos de Pasquali, composto por procedimentos teóricos, empíricos e analíticos ${ }^{(10)}$, realizado entre fevereiro e agosto de 2018. O conteúdo relacionou-se ao conjunto do construto técnico, o objetivo e a relevância do álbum seriado. A ordenação do conteúdo, a complexidade textual e a extensão do material estiveram associados à aparência ${ }^{(11)}$.

Para a elaboração, realizou-se uma revisão integrativa da literatura(12), para o levantamento de evidências disponíveis na literatura científica sobre as intervenções educativas realizadas pelos enfermeiros na promoção de saúde contra a violência contra a mulher na Atenção Básica, as quais foram utilizadas para fundamentar o conhecimento teórico descrito no material. Os resultados da revisão foram analisados pela Lei Maria da Penha ${ }^{(3)}$ e compuseram o conteúdo inicial do álbum seriado.

Em sequência, com auxílio de um designer gráfico, foi elaborada a arte do álbum seriado, por meio da confecção de figuras, formatação, configuração e diagramação das páginas. O designer desenvolveu as ilustrações baseadas em figuras reais e na descrição da pesquisadora, que objetivou retratar com precisão as informações obtidas na revisão integrativa levantada na literatura sobre a violência contra a mulher.

As ilustrações e a diagramação foram realizadas nos programas Adobe llustrator ( e Photoshop $\AA$. À medida que o profissional produzia as ilustrações, estas eram enviadas para aprovação ou possíveis alterações pela pesquisadora, até que foi alcançada a primeira versão do álbum seriado.

$\mathrm{Na}$ fase empírica, selecionou-se um grupo de especialistas para validar o álbum seriado. O levantamento para análise da elegibilidade dos participantes para a função de especialistas foi realizado por meio da Plataforma Lattes do Portal do Conselho Nacional de Desenvolvimento Científico e Tecnológico (CNPq) e do Banco de Teses da Coordenação de Aperfeiçoamento de Pessoal de Nível Superior (CAPES).

Para que o especialista fosse incluído, deveria pontuar minimamente cinco pontos, em consonância com o sistema validado de classificação e pontuação de especialistas e por amostragem do tipo bola de neve, na qual o participante selecionado indica ou sugere outros participantes, técnica bastante utilizada quando a população é composta por pessoas com características difíceis de serem encontradas ${ }^{(13,14)}$.

Para delimitação da quantidade de especialistas, adotou-se a recomendação de que o número esteja compreendido de 6 a 20, e que seja ímpar, para evitar empate de opiniões $^{(15,16)}$. Nesta fase, um grupo formado por 19 especialistas, com experiência em tecnologias educativas e/ou violência contra mulher, foi selecionado para avaliar o álbum seriado quanto aos objetivos, apresentação e estrutura e relevância.

Foi estabelecido o prazo de sete dias para devolução dos instrumentos de avaliação preenchidos e do Termo de Consentimento Livre e Esclarecido assinado. Para os especialistas que não atenderam a esse prazo, realizou-se novo contato e foi prorrogado o prazo por mais sete dias. Foram excluídos da pesquisa quatro especialistas que não responderam até o segundo prazo estabelecido. Portanto, participaram deste estudo 15 especialistas.

A coleta de dados foi realizada online, por correio eletrônico (e-mail), utilizando-se dois instrumentos adaptados: um para caracterização dos especialistas e o outro para avaliação do álbum seriado(17). Os especialistas avaliaram o álbum seriado conforme as seguintes seções $^{(18)}$ : objetivos - propósitos, metas ou afins que se deseja atingir com a utilização do álbum; estrutura e apresentação - forma de apresentar as orientações, organização geral, estrutura, estratégia de apresentação, coerência e formatação; e relevância - característica que avalia o grau de significação do material educativo apresentado. As respostas foram 
obtidas sob a forma de escala do tipo Likert, versão eletrônica, com pontuação gradual de 1 a 4 , onde 1 = inadequado, 2 = parcialmente adequado, 3 = adequado e 4 = totalmente adequado.

Para o procedimento analítico, utilizou-se a mensuração da validade dos itens analisados pelos especialistas, executada com base no Índice de Validade de Conteúdo (IVC) maior ou igual $0,78^{(19)}$. Após recebimento dos instrumentos preenchidos, iniciou-se a análise das informações. Para o cálculo do IVC por item, somou-se o número de respostas "3" ou "4" e dividiu-se pelo número total de respostas. Para a avaliação global do álbum seriado, foi utilizado o cálculo por meio da média dos valores dos itens calculados separadamente, por meio da soma de todos os IVCs calculados separadamente, dividido pelo número de itens considerados na avaliação(19). Os resultados foram apresentados por meio de tabelas a partir dos blocos: "Objetivos", "Estrutura e Apresentação" e "Relevância".

O projeto desta pesquisa recebeu aprovação do Comitê de Ética em Pesquisa, sob o parecer n. ${ }^{\circ}$ 2.516.799, de 27 de fevereiro de 2017.

\section{RESULTADOS}

Os 15 especialistas participantes eram da região Nordeste e Sudeste do Brasil, em sua maioria, eram $14(93,3 \%)$ do sexo feminino, $10(66,7 \%)$ enfermeiros e oito $(53,3 \%)$ tinham titulação de doutor. Predominou a faixa etária entre 30 a 50 anos, 11 (73,3\%) (Tabela 1).

Tabela 1 - Caracterização dos especialistas de conteúdo que validaram o álbum seriado. Teresina, PI, Brasil, 2018 (continua)

\begin{tabular}{llc} 
Variáveis & $\mathbf{N}$ & $\%$ \\
\hline Sexo & & \\
\hline Feminino & 14 & 93,3 \\
\hline Masculino & & 6,7 \\
\hline Formação & 10 & 66,7 \\
\hline Enfermagem & 5 & 33,3 \\
\hline Outros & & \\
\hline Idade & 2 & 13,3 \\
\hline$<30$ anos & 11 & 73,3 \\
\hline $30-50$ anos & 2 & 13,3 \\
\hline$>50$ anos & & \\
\hline Tempo de Formação & 5 & 33,3 \\
\hline$<10$ anos & 6 & 40 \\
\hline $10-15$ anos & 4 & 26,7 \\
\hline$>16$ anos & & \\
\hline Titulação & 8 & 53,3 \\
\hline Doutorado & 7 & 47,7 \\
\hline Mestrado & & \\
\hline Pesquisas publicadas em temas relacionados & & \\
\hline
\end{tabular}




\begin{tabular}{lcc}
\hline Violência contra a mulher & 8 & 42,1 \\
\hline Tecnologias educativas & 6 & 31,6 \\
\hline Validação de instrumento & 5 & 26,3 \\
\hline Experiência como docente em uma das áreas de interesse* & & \\
\hline Sim & 11 & 73,3 \\
\hline Não & 4 & 27,7 \\
\hline Experiência anterior com validação de materiais educativos & & \\
\hline Sim & 9 & 60 \\
\hline Não & 6 & 40 \\
\hline Experiência na área da educação em saúde & & \\
\hline Sim & 12 & 80 \\
\hline Não & 3 & 20 \\
*Violência contra a mulher, tecnologia educativas e validação de instrumento. &
\end{tabular}

No que diz respeito à avaliação sobre os objetivos, propósitos ou metas a serem atingidas com a utilização do álbum seriado, a classificação com maior frequência dos itens do instrumento foi totalmente adequado, o que traduziu a ideia de validação do material. O IVC médio desta avaliação foi 0,89 (Tabela 2).

Tabela 2 - Índice de Validade de Conteúdo (IVC) e avaliação dos especialistas ( $n=15)$ sobre os objetivos a serem atingidos com a utilização do álbum seriado. Teresina, PI, Brasil, 2018

\section{Objetivos}

Parcialmente Adequado adequado adequado

0,87 8

São coerentes com as necessidades dos 2 5 enfermeiros e das atitudes que estes devem ter no atendimento às mulheres vítimas de violência doméstica

\begin{tabular}{lllll}
\hline Promove mudança de comportamento e atitudes & 2 & 4 & 9 & 0,87 \\
\hline $\begin{array}{l}\text { Pode circular no meio científico na área de violência } \\
\text { doméstica contra mulher }\end{array}$ & 1 & 4 & 10 & 0,93 \\
\hline
\end{tabular}

\section{IVC médio}

Também foram avaliados itens relacionados à estrutura e apresentação, conforme demostrado na Tabela 3. Verificou-se que seis itens, do total de 10, alcançaram o IVC no valor máximo $(1,0)$, logo o álbum também foi validado com sucesso quanto à estrutura e apresentação. O IVC médio alcançado nesta avaliação foi 0,95 (Tabela 3). 
Tabela 3 - Índice de Validade de Conteúdo (IVC) e avaliação dos especialistas ( $n=15)$ sobre a estrutura e apresentação do álbum seriado. Teresina, PI, Brasil, 2018

\section{Estrutura e Apresentação}

Parcialmente adequado

Adequado Totalmente

IVC adequado

O material educativo é apropriado para o atendimento 0

8 1 e orientação de mulheres em situação de violência doméstica

\begin{tabular}{l}
$\begin{array}{l}\text { As informações apresentadas estão cientificamente } \\
\text { corretas }\end{array}$ \\
\hline
\end{tabular}

\begin{tabular}{llllc}
\hline Há uma sequência lógica do conteúdo proposto & 2 & 3 & 10 & 0,87 \\
\hline $\begin{array}{l}\text { O material está adequado ao nível sociocultural do } \\
\text { público-alvo* }\end{array}$ & 1 & 3 & 11 & 0,93 \\
\hline $\begin{array}{l}\text { As informações são bem estruturadas em concordância } \\
\text { e ortografia }\end{array}$ & 2 & 4 & 9 & 0,87 \\
\hline $\begin{array}{l}\text { O estilo de redação corresponde ao nível de } \\
\text { conhecimento do público-alvo* }\end{array}$ & 0 & 2 & 13 & 1 \\
\hline $\begin{array}{l}\text { Informações da capa, contracapa, agradecimentos e/ } \\
\text { ou apresentação são coerentes }\end{array}$ & 0 & 4 & 11 & 1 \\
\hline
\end{tabular}

\begin{tabular}{llllc}
\hline As ilustrações são expressivas e suficientes & 2 & 4 & 9 & 0,87 \\
\hline O número de páginas está adequado & 0 & 4 & 11 & 1 \\
\hline O tamanho do título e dos tópicos está adequado & 0 & 3 & 12 & 1 \\
\hline IVC médio & & & & 0,95
\end{tabular}

*Público-alvo: enfermeiros da atenção básica

Na Tabela 4, foi possível evidenciar a avaliação referente à relevância da tecnologia educativa, ou seja, o grau de significação do álbum seriado. O IVC médio desta avaliação foi 0,89 (Tabela 4).

Tabela 4 - Índice de Validade de Conteúdo (IVC) e avaliação dos especialistas $(n=15)$ sobre o grau de significação do álbum seriado (relevância). Teresina, PI, Brasil, 2018

\section{Relevância}

Parcialmente Adequado adequado

IVC

Os temas retratam os aspectos chaves (tipos de

1

Totalmente adequado

violência, prevenção e como agir perante uma

agressão) que devem ser reforçados

O material propõe aos enfermeiros da ESF adquirir conhecimento que os ajudará quanto às práticas clínicas no cuidado às mulheres vítimas de violência doméstica

O material aborda os assuntos necessários para a prevenção e enfrentamento à violência doméstica contra a mulher

IVC médio 
O IVC global do álbum seriado foi 0,93 , o que ratificou a validação de conteúdo e aparência. A versão final do álbum foi composta por 22 páginas: capa, ficha técnica, sumário, apresentação, páginas com informações sobre os tipos de violência contra a mulher, sobre medidas protetivas, medidas de amparo à mulher ofendida, situações de alerta, página de ajuda e referências. A Figura 1 apresenta o código QR para facilitar o acesso ao álbum seriado. Para isso, pode-se usar qualquer leitor de código QR e abrir o PDF. O link disponível no final do parágrafo, direciona o leitor para uma plataforma onde pode ser realizado o download do álbum seriado em formato PDF, https://drive.google. com/file/d/1pM9QyLsi8beFZEkq1y5GAS34LtSIDZjq/view?usp=sharing.

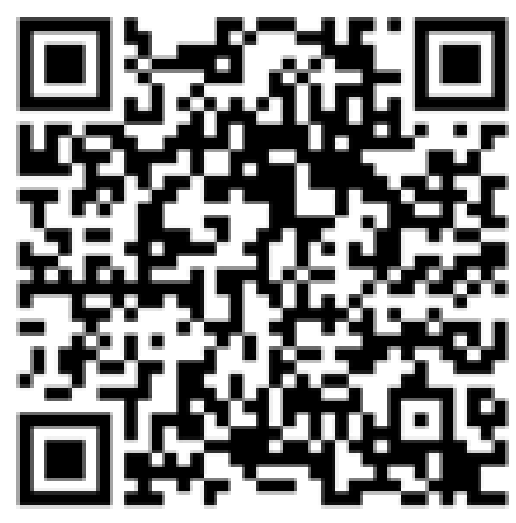

Figura 1 - QR Code da versão validada do álbum seriado. Teresina, PI, Brasil, 2018

Na Figura 2, estão representadas algumas ilustrações da versão validada do álbum seriado. 


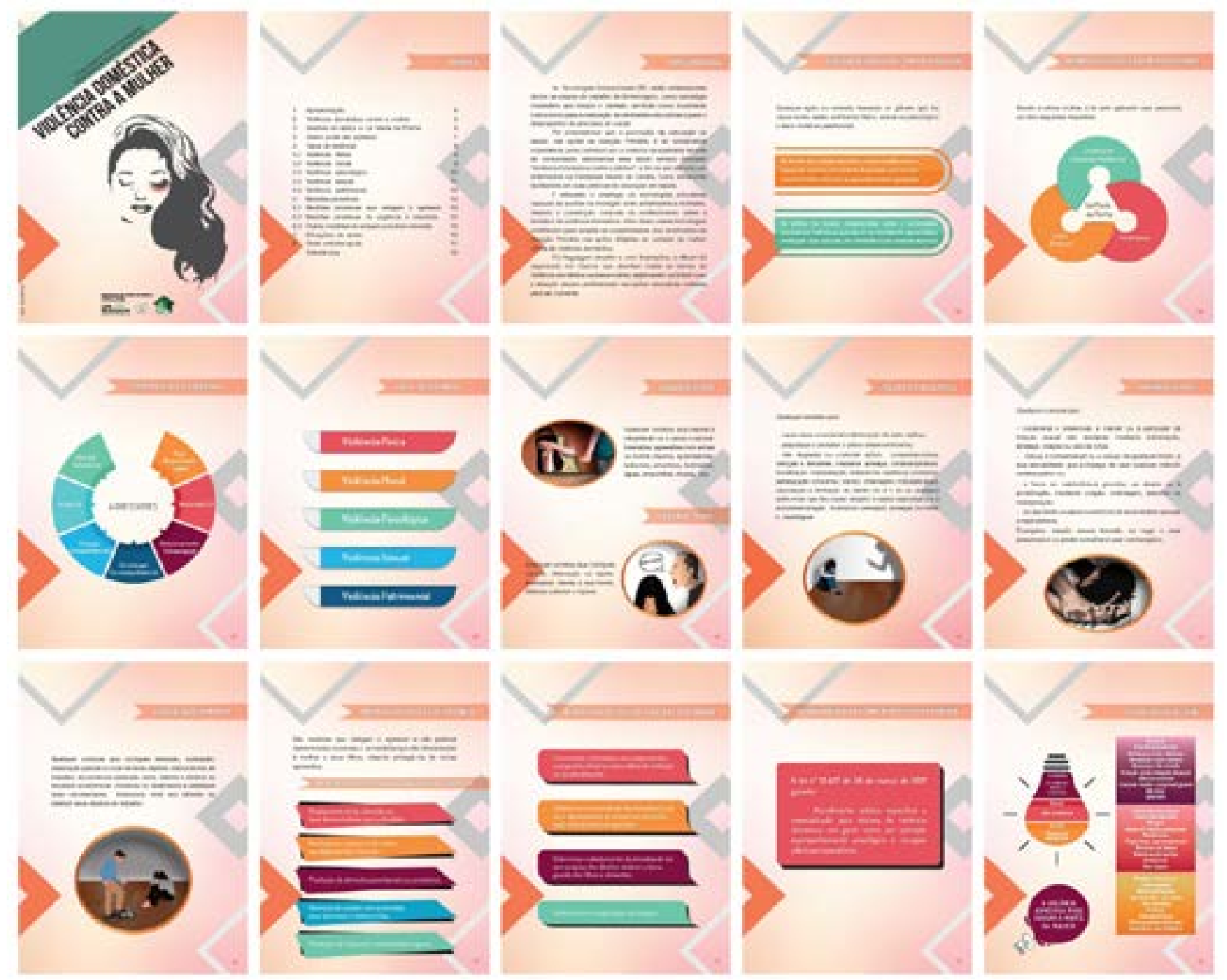

*Sequência das páginas da esquerda para direita: Capa. Sumário. Apresentação. Página 5 (Violência doméstica contra a mulher). Página 6 (Quando se aplica a Lei Maria da Penha). Página 7 (Quem pode ser agressor). Página 8 (Tipos de violência). Página 9 (Violência física e Violência moral). Página 10 (Violência psicológica). Página 11 (Violência sexual). Página 12 (Violência patrimonial). Página 13 (Medidas protetivas de urgência e Medidas protetivas que obrigam o agressor). Página 14 (Medidas protetivas de urgência à ofendida). Página 15 (Outras medidas de amparo à mulher ofendida). Página 16 (Situações de alerta).

Figura 2 - Representação ilustrativa da versão validada do álbum seriado. Teresina, PI, Brasil, 2018

\section{DISCUSSÃO}

No Brasil, a Estratégia Saúde da Família (ESF) tem favorecido a aproximação entre profissionais de saúde e mulheres em situação de violência, pois, no âmbito da Atenção Básica, a ESF constitui um espaço de concretização da Política Nacional de Atenção à Saúde da Mulher. Portanto, revela-se lugar privilegiado para desvelar problemas que anteriormente permaneciam na desinformação dos serviços, a exemplo da violência contra a mulher ${ }^{(20)}$.

Pesquisa desenvolvida em uma Unidade Básica de Saúde (UBS), localizada no distrito de Capão Redondo, em São Paulo-SP, região com altos índices de violência, cujos dados foram coletados por meio de entrevistas com 22 profissionais de saúde que integravam as equipes multiprofissionais e com 13 mulheres usuárias do serviço, evidenciou que a violência 
consiste num fenômeno "invisível" enquanto demanda nestes serviços. Constatou também que as práticas profissionais da ESF voltadas para as mulheres ainda são deficitárias, pois os profissionais não se encontram preparados para encarar a situação de violência vivenciada pela mulher, por entenderem que a violência é um problema social, cujo enfrentamento compete a outras áreas e não à da saúde. Dessa forma, no tocante à saúde das mulheres, na maioria das vezes, o atendimento se restringe especificamente aos aspectos biológico e reprodutivo ${ }^{(20)}$.

Neste aspecto, o álbum seriado foi elaborado como proposta para contribuir com a educação em saúde, a fim de que possa ser utilizado como tecnologia educativa pelos enfermeiros com atuação na Atenção Básica, como forma de facilitar o diálogo e promover reflexão e conhecimento sobre o tema nele disposto ${ }^{(8)}$.

$\mathrm{Na}$ etapa de validação, a avaliação dos especialistas foi relevante para o aperfeiçoamento do material e evidenciou que o álbum seriado constituiu um material de conteúdo e aparência válido, com adequados IVCs de item e global.

Durante a análise do álbum seriado, as principais observações levantadas pelos especialistas relacionam-se aos objetivos. Sobre esse aspecto, foi destacado que se tratava de um material educativo rico e que poderá ter relevância no meio acadêmico e profissional, mas foi sugerido enfatizar o papel do enfermeiro frente à violência contra a mulher e, como educador em saúde, delinear mais informações sobre as diretrizes práticas que os profissionais enfermeiros devem observar em relatos de violência.

Todavia, optou-se por não acatar estas sugestões, pois o álbum seriado elaborado apresentava como objetivo facilitar ao profissional enfermeiro a realização de atividades educativas relacionadas à saúde da mulher. Ressalta-se que esse estudo não teve como finalidade elaborar um manual ou protocolo de orientação das condutas a serem observadas pelos enfermeiros no atendimento nos casos de violência, mas sim trabalhar com a educação como forma preventiva.

Pesquisas revelaram a importância do papel da ESF na promoção à saúde e da necessidade de capacitação dos profissionais no contexto da violência contra a mulher, para uma intervenção adequada à promoção da saúde e à prevenção de agravos relacionados à violência contra a mulher no âmbito da saúde $e^{(21,22)}$.

No presente estudo, objetivou-se elaborar um álbum seriado para enfermeiros com informações a serem repassadas às mulheres durante as atividades de educação em saúde e, consequentemente, colaborar no processo de empoderamento da mulher para o enfrentamento do fenômeno. Entretanto, a elaboração e validação de um material educativo com orientações detalhadas a respeito dos procedimentos que os profissionais enfermeiros devem adotar acerca do cuidado à mulher em situação de violência doméstica, tais como acolhimento e notificações, conforme as sugestões dos especialistas, também é relevante, e poderá ser objeto de estudo em pesquisas posteriores.

Quanto à apresentação e estrutura do álbum seriado, um especialista sugeriu que o material seja descrito em formato de cartilha educativa. Todavia, o formato de álbum seriado foi mantido pois atende melhor ao objetivo da tecnologia educativa elaborada, visto que contém um maior número de ilustrações com o propósito de orientar e/ou facilitar enfermeiros nas práticas educativas de cuidado à saúde da mulher no âmbito da Atenção Básica.

Salienta-se que a abordagem do álbum seriado validado neste estudo é a educativa, a qual o enfermeiro poderá utilizar como uma ferramenta facilitadora do diálogo para explicitar às mulheres informações sobre violência doméstica.

Os especialistas ressaltaram a clareza, a objetividade, a facilidade de leitura e a compreensão do conteúdo apresentado. Além disso, quanto às ilustrações, os especialistas destacaram que as ilustrações se apresentam com uma boa aparência e pertinência, com cores firmes e com representações sobre a temática e que, portanto, havia uma boa 
viabilidade de aplicação no exercício profissional dos enfermeiros.

Ainda com relação às observações dos especialistas, foi acatada a sugestão de incluir na página "Onde solicitar ajuda" as ỦBSs, pois reforça o entendimento de que o setor saúde é um importante espaço para o desenvolvimento de ações de enfrentamento relacionados à violência contra a mulher, com enfoque preventivo e educativo. Ademais, sabe-se que as mulheres procuram com maior frequência as UBSs, locais favoráveis a fomentar ações preventivas e de promoção de saúde pela maior proximidade com a comunidade ${ }^{(4,23)}$.

Destaca-se que o álbum seriado proposto foi validado em conteúdo e aparência por especialistas (IVC global $=0,93$ ), portanto, pretende-se contribuir com as ações de educação em saúde, de forma atrativa e educativa, a respeito da violência doméstica contra mulher.

Ressalta-se que a Estratégia Saúde da Família compreende um modelo primário de assistência em saúde e que os enfermeiros possuem potencial no enfrentamento da violência contra a mulher. Selecionou-se pela elaboração e validação de uma tecnologia educativa relacionada à violência doméstica contra a mulher, visando auxiliar estes profissionais da Atenção Básica nas práticas de promoção em educação na saúde e, consequentemente, no enfrentamento desse problema ${ }^{(20)}$.

Em relação às limitações do estudo, destaca-se que os comentários e as sugestões dos especialistas com experiência na temática compreendem uma fonte significativa de informações de aprimoramento para o álbum seriado. Entretanto, nem todas as sugestões foram acatadas neste estudo, visto que alguns comentários não se relacionaram ao objetivo principal do material, o que pode indicar uma fragilidade no instrumento de coleta de dados. Além disso, destaca-se que, embora o número de estudos científicos relacionados à validação de materiais educativos na saúde venha ocupando maiores proporções, ainda há carência de publicações de validação de material que possibilitem auxiliar os enfermeiros na prática de educação em saúde, principalmente na área temática desse estudo, para uma fundamentação mais aprofundada nas análises desta pesquisa.

Como estudos futuros, sugere-se a validação do álbum seriado pelo público-alvo, visando aprimorar esta tecnologia elaborada e validada pelos especialistas.

\section{CONCLUSÃO}

O álbum seriado foi validado em conteúdo e aparência por especialistas com experiência na área de tecnologias educativas e/ou violência contra mulher, com IVC global de 0,93 , sugerindo que poderá ser utilizado em atividades de educação em saúde, com vistas à promoção de informações sobre a violência doméstica contra a mulher, favorecendo o processo de comunicação entre as mulheres e os profissionais de saúde, especialmente os enfermeiros, voltados à prevenção e enfrentamento do fenômeno.

Ressalta-se que as sugestões dos especialistas foram uma etapa essencial, que tornou o álbum seriado mais adequado aos enfermeiros e com maior rigor científico.

Como contribuição, o álbum seriado poderá ser utilizado nas atividades de educação em saúde por enfermeiros da Atenção Básica, com o objetivo de prevenir a violência doméstica contra a mulher.

O álbum seriado intitulado Violência Doméstica contra a Mulher foi considerado adequado para subsidiar os enfermeiros nas estratégias de educação e promoção da saúde, visto que o uso de tecnologias como instrumentos validados contribui com essa abordagem junto às equipes na Atenção Básica. 
1. Holanda ER de, Holanda VR de, Vasconcelos MS de, Souza VP de, Galvão MTG. Fatores associados à violência contra as mulheres na Atenção Primária à Saúde. Rev Bras Promoç Saúde. [Internet]. 2018 [acesso em 07 jul 2019]; 31(1). Disponível em: https://periodicos.unifor.br/RBPS/article/view/6580.

2. Nadda A, Malik JS, Rohilla R, Chahal S, Chayal V, Arora V. Study of domestic violence among currently married females of Haryana, India. Indian J Psychol Med [Internet]. 2018 [acesso em 07 jul 2019]; 40(6). Disponível em: http://www.ijpm.info/article.asp?issn=0253-7176; year=2018; volume=40;issue=6; spage $=5$ 34; epage $=539 ;$ aulast $=$ Nadda.

3. Cavalcanti LF, Moreira GAR, Flach RMD, Silva RM da, Vieira LJE de S. Gender violence against women and the dissemination of educational material. Saúde Foco. [Internet]. 2016 [acesso em 30 ago 2018]; 1(1). Disponível em: https://smsrio.org/revista/index.php/revsf/article/view/196.

4. Baptista RS, Chaves OBB de M, França ISX de, Sousa FS de, Oliveira MG de, Leite CC da S. Sexual violence against women: nurses' practice. Rev RENE. [Internet]. 2015 [acesso em 04 ago 2018]; 16(2). Disponível em: https://www.doi.org/10.15253/2175-6783.2015000200010.

5. Brasil. Lei $n^{\circ} 11.340$, de 7 de agosto de 2006. Cria mecanismos para coibir a violência doméstica e familiar contra a mulher, nos termos do $\S 80$ do art. 226 da Constituição Federal, da Convenção sobre a Eliminação de Todas as Formas de Discriminação contra as Mulheres e da Convenção Interamericana para Prevenir, Punir e Erradicar a Violência contra a Mulher[...]. Diário Oficial da União, Brasília, p. 1, 8 ago. 2006. Seção 1.

6. Brasil. Lei $n^{\circ} 10.778$, de 24 de novembro de 2003. Estabelece a notificação compulsória, no território nacional, do caso de violência contra a mulher que for atendida em serviços de saúde públicos ou privados. Diário Oficial da União, Brasília, p. 11, 25 nov. 2003. Seção 1.

7. Santos WJ dos, Oliveira PP de, Viegas SM da F, Ramos TM, Policarpo AG, Silveira EAA da. Domestic violence against women perpetrated by pntimate partner: professionals' social representations in primary health care. J. res.: fundam. care. online. [Internet]. 2018 [acesso em 30 ago 2018]; 10(3). Disponível em: http://dx.doi.org/10.9789/2175-5361.2018.v10i3.770-777.

8. Saraiva NCG, Medeiros CCM, Araujo TL de. Serial album validation for promotion of infant body weight control. Rev. Latino-Am. Enfermagem. [Internet]. 2018 [acesso em 30 ago 2018]; 26(1). Disponível em: http://dx.doi.org/10.1590/1518-8345.2194.2998.

9. Broch D, Crossetti M da GO, Riquinho DL. Reflections on violence against women in the perspective of Madeleine Leininger. Rev. Enferm. UFPE online. [Internet]. 2017 [acesso em 30 ago 2018]; 11(12). Disponível em: http://dx.doi.org/10.5205/1981-8963-v11i12a22588p5079-5084-2017.

10. Pasquali L. Instrumentação psicológica: fundamentos e práticas. Porto Alegre: Artmed; 2010.

11. Echer IC. Elaboração de manuais de orientação para o cuidado em saúde. Rev. Latino-Am. Enfermagem. [Internet]. 2005 [acesso em 01 set 2018]; 13(5). Disponível em: http://dx.doi.org/10.1590/ S0104-11692005000500022.

12. Mendes KDS, Silveira RC de CP, Galvão CM. Revisão integrativa: método de pesquisa para a incorporação de evidências na saúde e na enfermagem. Texto contexto - enferm. [Internet]. 2008 [acesso em 01 set 2018]; 17(4). Disponível em: http://dx.doi.org/10.1590/S0104-07072008000400018.

13. Fehring RJ. The Fering model. In: Carroll-jonhson RM. (Ed). Classification of the nursing diagnosis: proceeding of the tenth conferece. Philadelphia: Lippincott; 1994.

14. Polit DF, Beck CT. Fundamentos da pesquisa em enfermagem: avaliação de evidências na prática de enfermagem. 7. ed. Porto Alegre: Artmed; 2011.

15. Pasquali L. Psicometria: teoria e aplicações. Brasília (DF): UnB; 1997.

Viviane Maria de Pádua Rios Magalhães I Rosimeire Ferreira dos Santos I Carmen Viana Ramos I Lucíola Galvão Gondim Corrêa Feitosa I Eliana Campêlo Lago I Elayne Kelly Sepedro Sousa I Camila Aparecida Pinheiro Landim Almeida 
16. Viana HM. Testes em educação. São Paulo: IBRASA; 1982.

17. Oliveira MS de, Fernandes AFC, Sawada NO. Manual educativo para o autocuidado da mulher mastectomizada: um estudo de validação. Texto contexto - enferm. [Internet]. 2008 [acesso em 20 set 2018]; 17(1). Disponível em: http://dx.doi.org/10.1590/S0104-07072008000100013.

18. Medeiros RK da S, Ferreira Júnior MA, Pinto DP de SR, Vitor AF, Santos VEP, Barichello E. Modelo de validação de conteúdo de Pasquali nas pesquisas em enfermagem. Rev. Enf. Ref. [Internet]. 2015 [acesso em 20 set 2018]; 4(4). Disponível em: http://dx.doi.org/10.12707/RIV14009.

19. Alexandre NMC, Coluci MZO. Content validity in the development and adaptation processes of measurement instruments. Cienc. saude colet. [Internet]. 2011 [acesso em 30 ago 2018]; 16(7). Disponível em: http://dx.doi.org/10.1590/S1413-81232011000800006.

20. Oliveira RNG de, Fonseca RMGS da. Health needs: the interface between the discourse of health professionals and victimized women. Rev. Latino-Am. Enfermagem. [Internet] 2015 [acesso em 30 ago 2018]; 23(2). Disponível em: http://dx.doi.org/10.1590/0104-1169.3455.2555.

21. Paixão GP do N, Gomes NP, Diniz NMF, Lira MO de SC e, Carvalho MR da S, Silva RS da. Women experiencing the intergenerationality of conjugal violence. Rev. Latino-Am. Enfermagem [Internet]. 2015 [acesso em 01 set 2018]; 23(5). Disponível em: http://dx.doi.org/10.1590/0104-1169.0010.2626.

22. Gomes NP, Erdmann AL. Conjugal violence in the perspective of "Family Health Strategy" professionals: a public health problem and the need to provide care for the women. Rev. LatinoAm. Enfermagem [Internet]. 2014 [acesso em 01 set 2018]; 22(1). Disponível em: http://dx.doi. org/10.1590/0104-1169.3062.2397.

23. Guedes RN, Fonseca RMGS da, Egry EY. The evaluative limits and possibilities in the family health strategy for gender-based violence. Rev. Esc. Enferm. USP. [Internet]. 2013 [acesso em 01 set 2018]; 47(2). Disponível em: http://dx.doi.org/10.1590/S0080-62342013000200005.

Recebido: 09/11/2018

Finalizado: 02/03/2020

Autor Correspondente:

Camila Aparecida Pinheiro Landim Almeida

Universidade Católica Portuguesa

Porto, Portugal

E-mail: calmeida@porto.ucp.pt

Contribuição dos autores:

Contribuições substanciais para a concepção ou desenho do estudo; ou a aquisição, análise ou interpretação de dados do estudo - RFS, CVR

Elaboração e revisão crítica do conteúdo intelectual do estudo - ECL

Aprovação da versão final do estudo a ser publicado - LGGCF

Responsável por todos os aspectos do estudo, assegurando as questões de precisão ou integridade de qualquer parte do estudo - VMPRM, CAPLA 